\title{
DESIGNING OF THE STEPHENSON II SIX-LINK LINKAGE ACTUATOR FOR SERVO MECHANICAL PRESS
}

\author{
A. JOMARTOV ${ }^{1}$, A. TULESHOV ${ }^{2}$, N. JAMALOV ${ }^{3}$, M. KUATOVA ${ }^{4} \&$ A. KAIMOV ${ }^{5}$ \\ ${ }^{1,2}$ Professor, Institute Mechanics and Mechanical Engineering, Almaty, Kazakhstan \\ ${ }^{3}$ Associated Professor, Institute Mechanics and Mechanical Engineering, Almaty, Kazakhstan \\ ${ }^{4,5}$ Doctorant, Institute Mechanics and Mechanical Engineering, Almaty, Kazakhstan
}

Currently, servo mechanical presses with an actuator based on a slider-crank mechanism are widely used for stamping details. One of the major problems of these servo mechanical presses is inclination of slide caused by eccentric application of deforming force and total linear elastic deformation of the press links and stamps under load. The inclination of the slide of the servo mechanical press reduces the accuracy of punching and causes its jamming and lead to its breakage. To eliminate these problems, it is proposed to use Stephenson II six-bar linkage as an actuator of servo mechanical press. The scheme structure of the actuator of servo mechanical press with two connecting rods and one crank based on the Stephenson II six-bar linkage is obtained. Synthesis of the Stephenson II six-bar linkage was carried out. As a result of synthesis, a new actuator of servo mechanical press on the base of the Stephenson II six-bar linkage was obtained and its prototype was made. The prototype of the new actuator of servo mechanical press based on the Stephenson II six-bar linkage was tested. Testing of the prototype of the new actuator of servo mechanical press showed a good distribution of the efforts applied during the presswork and a better tolerance of the eccentric load.

KEYWORDS: Servo Mechanical Press, Actuator, Stephenson II Six-bar Linkage, Slide \& Tilt
\end{abstract}

Received: Jan 27, 2020; Accepted: Feb 17, 2020; Published: Mar 16, 2020; Paper Id.: IJMPERDAPR202053

\section{INTRODUCTION}

Servo mechanical press is a metal forming equipment that uses a servomotor as a drive [Altan 2007; Halicioglu et al. 2016]. Unlike a conventional mechanical crank press (Figure 1a), the servo mechanical press does not contain such units as: flywheel, brake, clutch (Figure 1b) [Halicioglu 2015]. In the servo mechanical press (Figure 1b), the servomotor is mounted on the pinion shaft of the gear reduction, and through the slider-crank mechanism, it carries out the stamping process. The servomotor operates according to a predetermined program, providing a stamping process. In the servo mechanical press, the movement and speed of the slide are controlled, and it is possible to carry out a specified dwell. The servo mechanical press has the flexibility of a hydraulic press for payload and the speed and accuracy of conventional mechanical presses. Servo mechanical press has the ability to provide the optimal law of motion of the slide to perform the required metal forming process. The use of servo mechanical press in manufacturing industries allows reducing energy consumption, shock loads, vibrations and increase the accuracy of stamping [Groseclose 2009; Osborn et al. 2008]. 


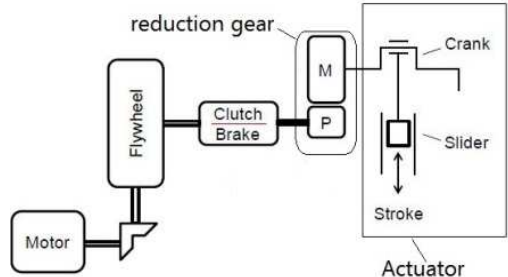

(a)

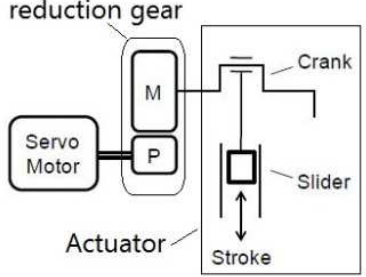

(b)

Figure 1: Press Schemes a- Conventional Mechanical Press, b- Servo Mechanical Press.

The servo mechanical press consists of a servo motor, reduction gear and actuator as shown in Figure 1b. Usually, the simplest slider-crank mechanism is used as an actuator in a servo mechanical press. The slider-crank mechanism is simple and reliable, but due to the structure of the mechanism during the operation of the servo mechanical press, slide tilts occur. A feature of the servo mechanical press during metal stamping is a complex programmable movement, in which there are large accelerations and decelerations, stops and reverse. The reliable operation of the servo mechanical press depends on the structure of the actuator.

The accuracy of stamping of the servo mechanical press is the main parameter that affects the quality of the products. Tilt of the slide due to the influence of eccentric force and the rigidity of the press frame are the main factors affecting the accuracy of the servo mechanical press [Altan 2007].

Purpose of this paper is to increase the accuracy of the servo mechanical press by reducing the tilt of the slide of actuator under the influence of eccentric force. Tilt at eccentric application of force is less in the actuator of servo mechanical presses with two and four connecting rods, thanks to the better direction of the slide and less loads on the guide rails in comparison with one connecting rod. In case of eccentric application of the load on the stamp, actuator of servo mechanical press with two connecting rods, as shown in Figure 2a have an advantage over servo mechanical press actuator with one connecting rod, as shown in Figure $2 \mathrm{~b}$. In actuator of servo mechanical press with two connecting rods forces act on the slide at two points, as shown in Figure 2a, which significantly reduces the possibility of its tilt. In general, the resulting stamping force coincides with the center of the slide of actuator of servo mechanical press. However, due to the complex and asymmetric shape of manufactured part, the load center shifts and an eccentric force occurs. This is especially noticeable in the actuator of servo mechanical press with one connecting rod. The slide under the influence of eccentric force has the tilt, as shown in Figure $3 \mathrm{a}$.

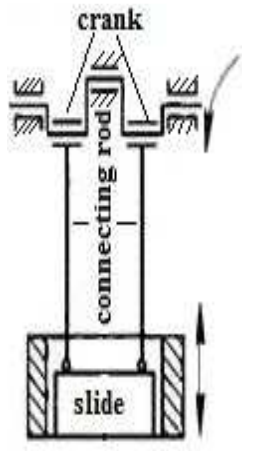

(a)

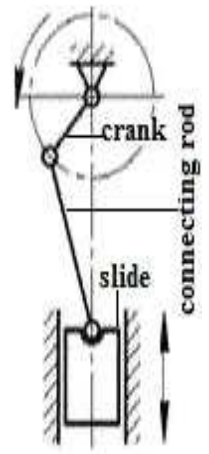

(b)

Figure 2: Kinematic Schemes of the Actuator of Servo Mechanical Press;

a) with Two Cranks and Two Connecting Rods;

b) with One Crank and One Connecting Rod. 


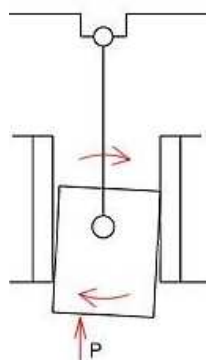

(a)

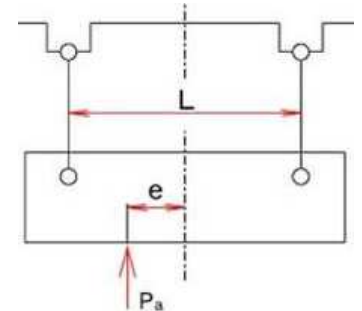

(b)

Figure 3: Actuator of Servo Mechanical Press;

a) with One Crank and One Connecting Rod,

b) with Two Cranks and Two Connecting Rods.

To reduce the impact of eccentric force on the slide, it is necessary to reduce the payload or switch to the use of the actuator of servo mechanical press with two connecting rods.

The permissible eccentric load of the actuator of servo mechanical press with two cranks and two connecting rods as shown in Figure $3 b$ is calculated by next formula [Misumi 2019].

$$
P_{a}=\frac{1}{2} P K \frac{L}{e+\frac{L}{2}}
$$

where $P$ - nominal pressure, $P_{a}$ - permissible eccentric load, $K$ - coefficient (see Table 1.), $e$-amount of eccentricity, $L$-distance between connecting rods. Here is $P_{a} \leq P$

Table 1: Values of Coefficient

\begin{tabular}{|c|c|}
\hline Amount of eccentricity $\boldsymbol{e}[\mathrm{mm}]$ & Coefficient $K$ \\
\hline 30 & 0.91 \\
\hline 50 & 0.86 \\
\hline 60 & 0.83 \\
\hline 75 & 0.80 \\
\hline 90 & 0.77 \\
\hline 100 & 0.75 \\
\hline
\end{tabular}

The advantage of the actuator of servo mechanical press with two connecting rods on act to eccentric force on the slide is obvious. In the actuator of servo mechanical press with two connecting rods, the load on slide guide rail is reduced and thus the possibility of its jamming is reduced. Disadvantages of the actuator of servo mechanical press produced by the industry with two connecting rods are: high cost, complexity of construction, large size. In this regard, designing of new actuator of servo mechanical press with two connecting rods based on linkages is an important task. To design the actuator of servo mechanical press with one crank and two connecting rods, we use Stephenson chain of six-bar linkage.

\section{STEPHENSON II SIX-BAR LINKAGE}

For the choice of the structure scheme of the linkages of the actuator of servo mechanical press with two connecting rods and one crank, we use Stephenson II six-bar linkage [Hu et al. 2016).]. Figure 4a shows Stephenson chain of a six-bar linkage, consisting of four binary links, two separated ternary links and seven revolute joints. When selecting link 6 as a fixed frame, link 5 as an input crank and link 1 as an output link, we obtain Stephenson II six-bar linkage [Hsieh et al. 2011; Soong et al. 2010]. If the length of the output link 1 is increased to infinity, then the output link will be in the form of a slide. 


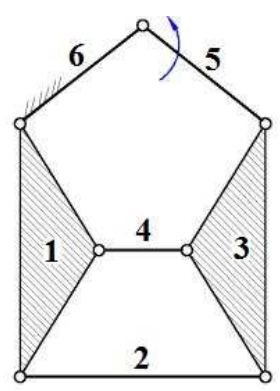

(a)

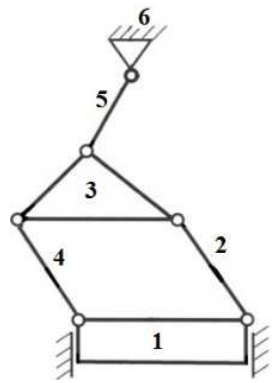

(b)

Figure 4: a) Stephenson Chain of a Six-Bar Linkage,

b) Stephenson II Six-Bar Linkage.

The obtained Stephenson II six-bar linkage, as shown in Figure 4b, can be used for the actuator of servo mechanical press.

\subsection{Kinematic Analysis of Stephenson II six-Bar Linkage}

Let's consider the kinematic analysis of Stephenson II six-bar linkage as shown in Figure 5, changeable contour $B B^{\prime} C^{\prime} C$ of which is a parallelogram. In this case, the problem of kinematic analysis can be solved analytically through elementary functions.

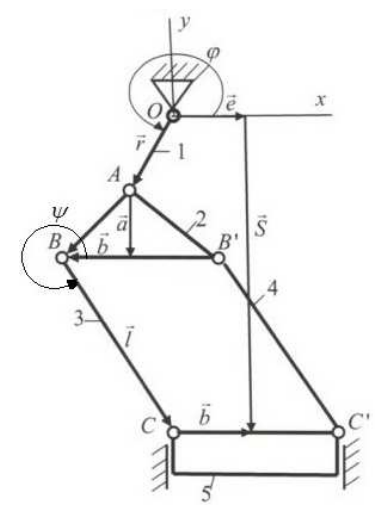

Figure 5: Stephenson II Six-Bar Linkage.

Let's write the equations of contour closeness of Stephenson II six-bar linkage as shown in Figure 5, in a vector form

$$
\vec{r}+\vec{a}+\vec{b}+\vec{l}-\vec{b}=\vec{S}+\vec{e}
$$

Projecting Eq. (1) on the coordinate axes, we obtain

$$
\left\{\begin{array}{l}
r \cos \varphi+l \cos \psi=e \\
r \sin \varphi-a+l \sin \psi=-S
\end{array}\right.
$$

From Eq. (2) you can get the desired laws of motion $S=S(\varphi), \psi=\psi(\varphi)$

$$
\left\{\begin{array}{l}
S=a-r \sin \varphi-l \sin \psi \\
\cos \psi=-\frac{1}{l}(e-r \cos \varphi)
\end{array}\right.
$$

The expression Eq. (3) can be written as 


$$
\left\{\begin{array}{l}
S=a-r \sin \varphi \pm \sqrt{l^{2}-(\mathrm{e}-r \cos \varphi)^{2}} \\
\psi= \pm \arccos \left[\frac{1}{l}(e-r \cos \varphi)\right]
\end{array}\right.
$$

Signs \pm correspond to different assemblies of the mechanism. To determine velocities and accelerations, we differentiate Eq. (3) according to the generalized coordinate $\varphi$

$$
\begin{aligned}
& \left\{\begin{array}{l}
S^{\prime}=-r \cos \varphi-l \cos \psi \cdot \psi^{\prime} \\
\psi^{\prime} \sin \psi=-\frac{r}{l} \sin \varphi
\end{array}\right. \\
& \left\{\begin{array}{l}
S^{\prime \prime}=r \sin \varphi+l \sin \psi \cdot \psi^{\prime 2}-l \cos \psi \cdot \psi^{\prime \prime} \\
\psi^{\prime \prime} \sin \psi+\cos \psi \cdot \psi^{\prime 2}=-\frac{r}{l} \cos \varphi
\end{array}\right.
\end{aligned}
$$

For the central mechanism, when $e=0$, Eqs. (4) are simplified a little

$$
\left\{\begin{array}{l}
S=a-r \sin \varphi \pm \sqrt{l^{2}-r^{2} \cos ^{2} \varphi} \\
\psi= \pm \arccos \left[\frac{r}{l} \cos \varphi\right]
\end{array}\right.
$$

In contrast to the usual crank-slider mechanism in formulas Eq. (3) and Eq. (7) parameter $a$ is included.

Velocities can be explicitly obtained

$$
\left\{\begin{array}{l}
S^{\prime}=-r \cos \varphi \pm \frac{r^{2} \sin \varphi}{2 \sqrt{l^{2}-r^{2} \cos ^{2} \varphi}} \\
\psi^{\prime}=\mp \frac{r \sin \varphi}{\sqrt{l^{2}-r^{2} \cos ^{2} \varphi}}
\end{array}\right.
$$

Accelerations can be obtained after differentiation Eq. (8) by $\varphi$

$$
\left\{\begin{array}{c}
S^{\prime \prime}=r \sin \varphi \pm r^{2}\left(\begin{array}{c}
\frac{\cos \varphi}{\sqrt{l^{2}-r^{2} \cos ^{2} \varphi}}- \\
-\frac{r^{2} \sin ^{2} \varphi \cos \varphi}{2\left(l^{2}-r^{2} \cos ^{2} \varphi\right)^{3 / 2}}
\end{array}\right) \\
\psi^{\prime \prime}= \pm r\left(\frac{\cos \varphi}{\sqrt{l^{2}-r^{2} \cos ^{2} \varphi}-\frac{r^{2} \sin ^{2} \varphi \cos \varphi}{2\left(l^{2}-r^{2} \cos ^{2} \varphi\right)^{3 / 2}}}\right)
\end{array}\right.
$$

The linear velocity of the slide is determined by the formula:

$$
\dot{S}=\frac{d S}{d t}=S^{\prime} \cdot \omega
$$


where $\omega=\frac{d \varphi}{d t}$ - angular velocity of a crank shaft. The linear acceleration of the slide is determined by the formula:

$$
\begin{aligned}
& \ddot{S}=\frac{d^{2} S}{d t^{2}}=S^{\prime \prime} \cdot \omega^{2}+S^{\prime} \varepsilon \\
& \text { where } \varepsilon=\frac{d^{2} \varphi}{d t^{2}}-\text { angular acceleration of the crank shaft. }
\end{aligned}
$$

\subsection{New Actuator of Servo Mechanical Press on the Basis of Stephenson II Six-Bar Linkage}

As mentioned above, the actuator of servo mechanical press with two connecting rods have great advantages compared to the actuator with one connecting rod, thanks to a better distribution of forces on the slide and, accordingly, lower loads on the guide slide. Initial data for the synthesis: the law of motion $S=S(\varphi)$, (See Figure 6) in the segment $0 \leq \varphi \leq 2 \pi$. Slidestroke $S_{\max }=120 \mathrm{~mm}$. Angular velocity of crank is constant $\omega=\dot{\varphi}=10 \mathrm{rad} / \mathrm{s}$.

To develop a new actuator of servo mechanical press, the Stephenson II six-bar linkage was synthesized (Figure 7), where the notation $L 12$ is distance between point 1 and 2 and $L 23$ is the distance between point 2 and 3 , etc.

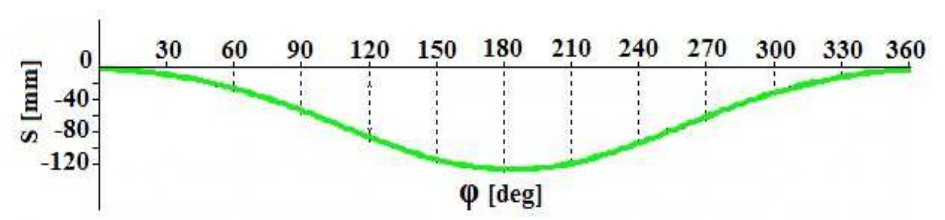

Figure 6: The Law of Motion of the Stephenson II Six-Bar Linkage.

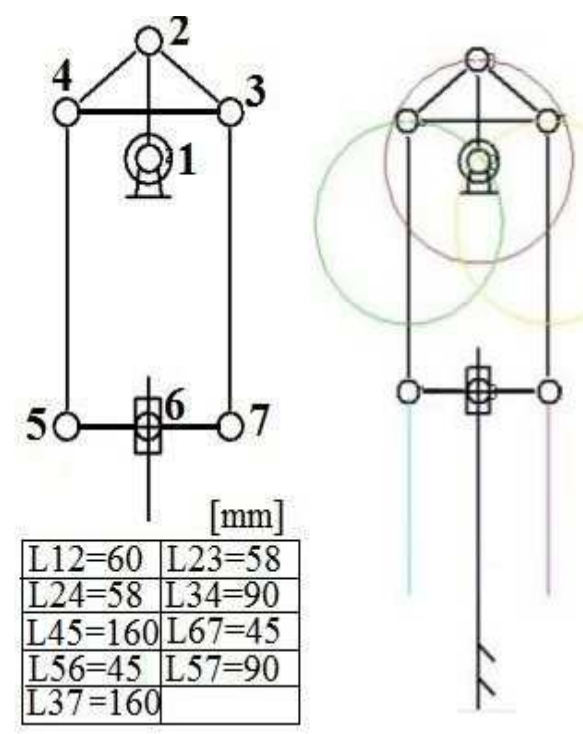

Figure 7: Synthesized Stephenson II Six-Bar Linkage.

In Figure 8 shows the graphs of the velocity $\dot{S}$ (a) and acceleration $\ddot{S}$ (b) of the synthesized Stephenson II sixbar linkage. 


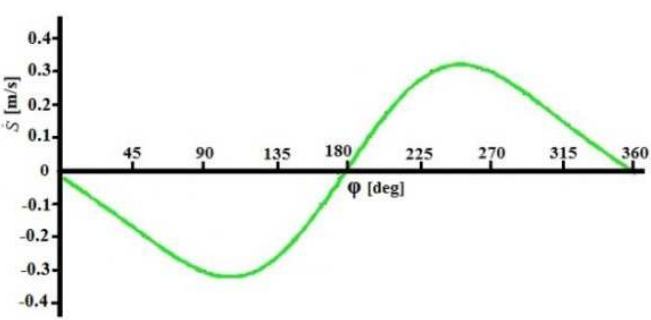

(a)

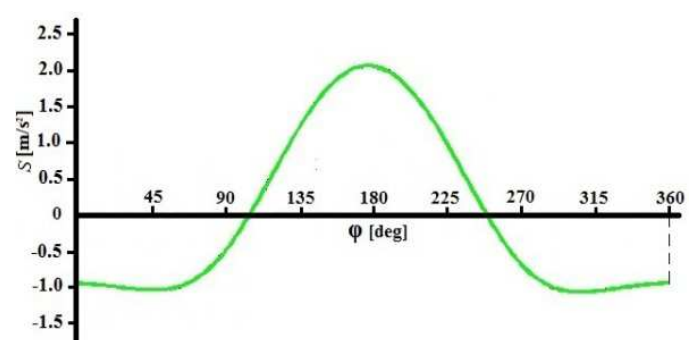

(b)

Figure 8: Graphs of the Synthesized Stephenson II Six-Bar Linkage: a - Velocity, b - Acceleration.

\section{3D Model of the of Servo Mechanical Press}

Kinematic scheme of the new actuator of servo mechanical press based on the Stephenson II six-bar linkage is shown in Figure 9

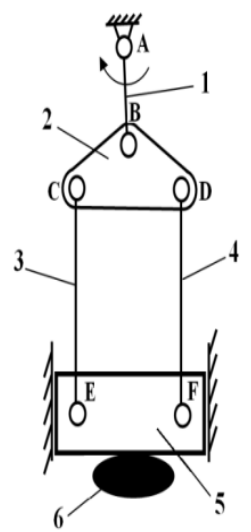

Figure 9: Kinematic Scheme of the New Actuator of Servo Mechanical Press: 1 - Crank, 2 - Ternary Link, 3,4 - Connecting Rods, 5 - Slide A,B,C,D,E,F - Revolute Joints.

The linkage of the new actuator of servo mechanical press works as follows. At full rotation the crank 1 through the ternary link 2 and connecting rods 3 and 4 transmits the movement of the slide 5, which in turn affects the processed object 6 . With that, at the moment of contact of the slide 5 with the object under the process 6 the connecting rods 3 and 4 are in a parallel position, which ensures an even distribution of loads both on the processed object 6 and between the links of the actuator of servo mechanical press.

To develop the 3D model of servo mechanical press with actuator based on Stephenson II six-bar linkage, the Autodesk Inventor system was used. At the beginning, 3D model of all links of the linkage and structure of the press was constructed and computer assemblage was carried out. Figure 10a shows the top of the press. When designing the rods, a rolled channel 100x46 was used. Similarly, the base of the press was constructed using the same rolled channel as shown in Figure 10b.

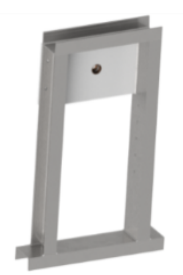

(a)

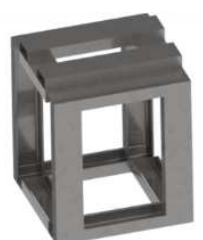

(b)

Figure 10: Construction; a) The Top of the Press, b) The Base of the Press. 
In Figure 11 shows a 3D model of actuator of servo mechanical press

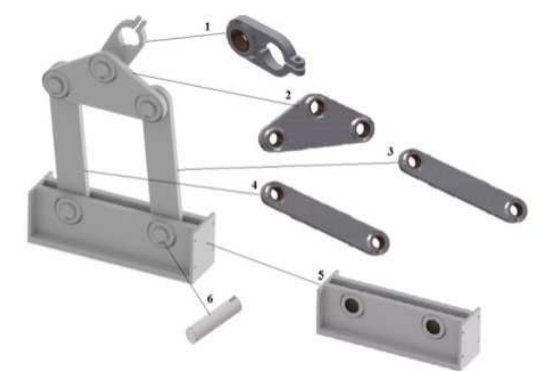

Figure 11: Construction of Actuator of Servo Mechanical Press:

1-Crank, 2- Ternary Link, 3,4 - Connecting Rod, 5- Slide, 6 - Joint Pin.

The full view of the entire servo mechanical press in Autodesk Inventor is shown in Figure 12.

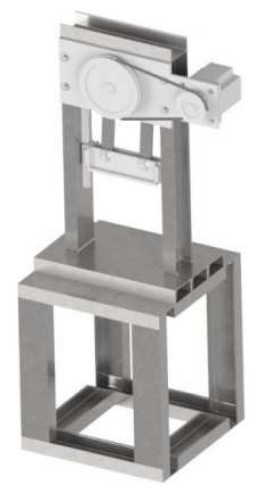

Figure 12: Construction of Servo Mechanical Press in Autodesk Inventor.

A prototype of the actuator of servo mechanical press is made as shown in Figure 13.

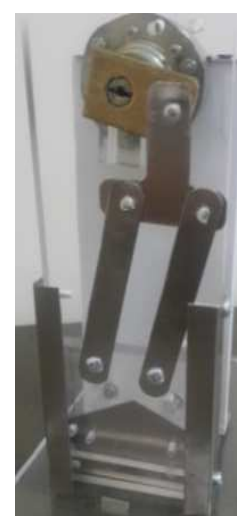

Figure 13: A Prototype of the Actuator of Servo Mechanical Press.

Testing of the prototype of the actuator of servo mechanical press showed a good distribution of the efforts applied during the presswork and a better tolerance of the eccentric load.

\section{CONCLUSIONS}

To increase the accuracy of stamping of servo mechanical press, it is necessary to reduce the tilt of the slide under the influence of eccentric force. It was established that the tilt of the slider with application of eccentric force is less in servo mechanical press with actuator of two connecting rods, compared with presses with one connecting rod. To improve the accuracy of stamping servo mechanical press, it is proposed to use Stephenson II six-bar linkage for the actuator of servo 
mechanical press. Synthesis of the Stephenson II six-bar linkage was carried out. 3D model of the servo mechanical press with the new actuator, based on Stephenson II six-bar linkage was created on Autodesk Inventor. Prototype of the new actuator of servo mechanical press was made. Tests were carried out, which showed a good distribution of the efforts applied during the presswork and a better tolerance of the eccentric load. The main result of the work is the design of a new actuator of servo mechanical press with one crank and two connecting rods.

\section{ACKNOWLEDGEMENTS}

This research was funded by the Science Committee of the Ministry of Education and Science of the Republic of Kazakhstan under grant no. AP05134959

\section{REFERENCES}

1. Altan, T. (2007). Servo press forming applications: Part I-II-III, Stamping Journal

2. Osakada, K., Mori, K., Altan, T., Groche, P. (2011). Mechanical servopress technology for metal forming. CIRP Ann Manuf Techno, 160(2), 651-672

3. Hallcloglu, R., Dulger, L. C., Bozdana, A. T. (2016). Mechanisms, classifications, and applications of servo presses: A review with comparisons. Proceedings of the Institution of Mechanical Engineers, Part B: Journal of Engineering Manufacture, 230(7), 1177-1194

4. Halicioglu, R. (2015). Design, synthesis and control of a mechanical servo press: An industrial application, PhD Thesis: Gaziantep University.

5. Groseclose, A. (2009). New applications for servo-driven presses: Part I: Stamping of automotive components. Stamping Journal, 14-15.

6. Saritha, P., et al. "Mechanical Characterization and Wear Behaviour of AL7075 Alloy Reinforced with Alumina and Molybdenum Disulphide."

7. Osborn, A., Paul, S. (2008). Servo-press technology: Drive design and performance. Metal Forming, 42, 18-23

8. Misumi technical tutorial, from http://www.misumi-techcentral.com/tt/en/press/, accessed on 2019-05-22.

9. G. N. Sandor \& A. G. Erdman.(1984). Advanced mechanism Design: Analysis and Synthesis-Vol. II, Pearson;1st edition.

10. Hu, J., Sun, Y., Cheng, Y. (2016). High mechanical advantage design of six-bar Stephenson mechanism for servo mechanical presses. Advances in Mechanical Engineering, 8(7), 1-12

11. Hor, Kamal KIS, and Rekha JHA. "Control of DC Servomotor using Relay and Pole Placement Method by MATLAB Simulink."

12. Hu, J., Sun, Y., Cheng, Y., Ruan, W. (2011). Numerical Analysis on Transmission Characteristics of Stephenson's Six-bar Punching Mechanism with Servo Input. Applied Mechanics and Materials, 86, 623-628

13. Hsieh, W. H., Tsai, C. H. (2011). On a novel press system with six links for precision deep drawing. Mech. Mach. Theory, 46, 239-251

14. Rai, K. B., and P. R. Dewan. "Parametric optimization of WEDM using grey relational analysis with Taguchi method." IMPACT: International Journal of Research in Engineering \& Technology, 2, 109116 (2014).

15. Soong, R. Ch. (2010). A new design for single DOF mechanical presses with variable speeds and length adjustable driving links. Mech. Mach. Theory, 45, 496-511 


\section{AUTHOR'S PROFILE}

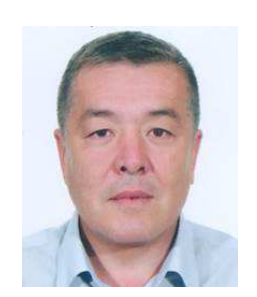

Assylbek Jomartov is Prof., Dr. Sc. and deputy of general director of Institute of Mechanics and Mechanical Engineering. His research interests cover of the dynamics of automatic machines with elastic links with the timing diagram for the development of mechanisms for the dynamic analysis of automatic machines. He has published 160 scientific articles and abstracts (11 of them in the Web of Science database and 16 in the Scopus database), two monographs, and 13 inventions. He took an active part in many engineering developments that were implemented in production and brought economic benefits to the national economy. He is a domestic scientific consultant for two Phd doctoral students.

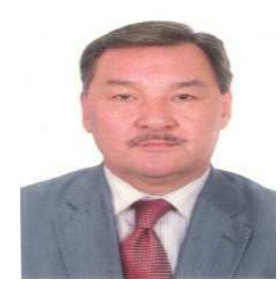

AmandykTuleshov is Prof., Dr. Sc. and general director of Institute of Mechanics and Mechanical Engineering, Almaty, Kazakhstan. Institute of Mechanics and Mechanical Engineering, Almaty, Kazakhstan, Kurmangazy str. 29 Almaty, 050010. Direction of scientific activity: kinematics and dynamics of linkage mechanisms, dynamics and control of continuous and rotary machines, mathematical and computer modeling of mechanical systems, robotics, intelligent and CAD systems. He published more than 200 scientific works, of which 8 monographs, 14 patents, of which 10 patents of the Republic of Kazakhstan, 2 foreign patents. He has 5 publications in international journals with a high impact factor.

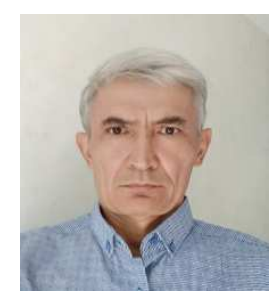

NutpullaJamalov is a associate professor in Institute of Mechanics and Mechanical Engineering, Almaty, Kazakhstan. Institute of Mechanics and Mechanical Engineering, Almaty, Kazakhstan, Kurmangazy str. 29 Almaty, 050010. His area of interest is the theory of mechanisms and machines, robotics. He has more than 100 scientific papers, including 24 inventions, 15 publications of inventions are included in the Web of science database, 3 in the Scopus database.

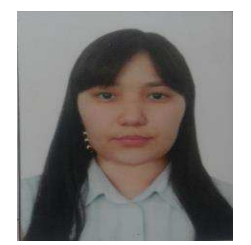

KuatovaMoldir is third-year PhD-student of Al-Farabi Kazakh National University, by specialty Mechanics. She graduated 
from bachelor and masters of Al-Farabi Kazakh National University by Materials Science and Technology of New Materials. Kuatova M. work as an engineer in "U.A. Joldasbekov Institute of Mechanics and Mechanical Engineering", a senior assistant in Science Research Institute of Experimental and Theoretical Physics, a senior researcher in LLP Scientific innovation center "Almas". She has 10 publications of which 4 in Scopus database and 4 patents.

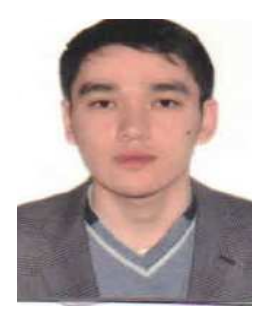

Ablay Kaimovis third-year PhD-student of Institute of Mechanics and Mechanical Engineering, by specialty Mechanics. He graduated from bachelor and masters of al-Farabi Kazakh National University by Materials Science and Technology of New Materials. Kuatova M. works as an engineer in Institute of Mechanics and Mechanical Engineering”. He has 8 publications of which 2 in Scopus database. 
